\title{
Clinical and Laryngotracheoscopic Evaluation of Children with Cerebral Palsy Using Intraparotid Injections of Botulinum Toxin Type A for Drooling Control
}

\author{
Juliana Benthien Cavichiolo ${ }^{*}$, Sérgio Bernardo Tenório², Elise Zimmermann ${ }^{3}$, \\ Fabiano Bleggi Gavazzoni ${ }^{1}$, Rodrigo Guimarães Pereira ${ }^{4}$, Elmar Fugmann ${ }^{5}$ \\ ${ }^{1}$ Department of Clinical Surgery, Hospital Pequeno Príncipe, Curitiba, Brasil \\ ${ }^{2}$ Department of Anesthesiology, Hospital de Clínicas da UFPR and Hospital Pequeno Príncipe, Curitiba, Brasil \\ ${ }^{3}$ Department of ENT Surgery, Hospital Pequeno Príncipe, Curitiba, Brasil \\ ${ }^{4}$ Department of Otorhinolaryngology, Hospital Pequeno Príncipe, Curitiba, Brasil \\ ${ }^{5}$ Department of Clinical Surgery, Hospital de Clínicas da UFPR, Curitiba, Brasil \\ Email: ^juliana.cavichiolo@outlook.com
}

How to cite this paper: Cavichiolo, J.B., Tenório, S.B., Zimmermann, E., Gavazzoni, F.B., Pereira, R.G. and Fugmann, E. (2018) Clinical and Laryngotracheoscopic Evaluation of Children with Cerebral Palsy Using Intraparotid Injections of Botulinum Toxin Type A for Drooling Control. Surgical Science, 9, 44-51.

https://doi.org/10.4236/ss.2018.91005

Received: November 21, 2017

Accepted: January 28, 2018

Published: January 31,2018

Copyright $\odot 2018$ by authors and Scientific Research Publishing Inc. This work is licensed under the Creative Commons Attribution International License (CC BY 4.0).

http://creativecommons.org/licenses/by/4.0/

(c) (7) Open Access

\begin{abstract}
Introduction: Medical literature shows consistent data on the use of botulinum toxin for the treatment of drooling, especially in patients with neurological disorder. However, any trial evaluated the reduction of sialorrhea through laryngotracheoscopy. Objective: To evaluate the reduction of salivation and aspiration in children with cerebral palsy submitted to intraparotid injection of botulinum toxin. Methods: A prospective cohort study including 31 pediatric patients with cerebral palsy who complained of sialorrhea and were submitted to an intraparotid injection of botulinum toxin type A. It was analysed the reduction of the number of bibs and the amount of saliva in the larynx and trachea through a laryngotracheoscopic examination. Results: There was a reduction in the number of bibs from 7.35 to 4 after application of BoNT/A, with $p$-value $<0.001$. The age of the patients did not influence on the number of bibs. $71 \%$ of the patients reduced the amount of saliva in laryngotracheoscopic examination. The number of normal exams increased from $3.2 \%$ to $38.7 \%$ and aspiration fell from $38.7 \%$ to $12.9 \%$. Conclusion: Application of botulinum toxin type A is a good method for temporary control of salivation in children with neurological disorders.
\end{abstract}

\section{Keywords}

Botulinum Toxin, Sialorrhea, Laryngotracheoscopy 


\section{Introduction}

Sialorrhea is uncommon among normal children after six months of age, but it is a common complaint among patients with neurological disorders. It can affect between $10 \%$ and $70 \%$ of children with cerebral palsy or patients with congenital or acquired neurological disorders [1]. Several drugs are used in the treatment of sialorrhea, one of the most modern drugs is botulinum toxin.

Botulinum toxin type A is a product of biological origin obtained from the anaerobic bacterium Clostridium botulinum. This toxin binds to the presynaptic region of the motor end plate, preventing the release of acetylcholine $(\mathrm{ACH})$ by the neuron [2]. The $\mathrm{ACH}$ is a neurotransmitter peptide, and its main action is to stimulate the contraction of striated muscles and also the secretion of exocrine glands, like the salivary and sweat glands. The blockage by the toxin causes a local chemo denervation. The effect usually appears from 7 to 10 days after the application and has a variable duration. The maximum duration is about 6 months.

This toxin has many applications in medicine and chronic sialorrhea is one of them. Studies in this area have been developed since 1997. Sialorrhea is an extremely common problem in neurological patients and brings disturbances to their family. The recurrent respiratory symptoms, the frequent use of antibiotics for pneumonia, the constant change of clothes and wet bibs, may cause constant discomfort for parents and patients, besides cough and other oral lesions which are typical of hyper salivation [1] [2].

The sialorrhea can be caused by neuromuscular dysfunction, hypersecretion or anatomical alteration [3]. Neurological diseases are the most common causes of chronic salivation, being observed in patients with cerebral palsy, Parkinson disease, stroke, multiple sclerosis, and others. In neurological disease, there usually is no increase of saliva production, but inability of the patient to swallow it [4]. It happens mainly in patients with dysphagia leading to an even bigger problem, saliva aspiration, which is often silent [5].

Saliva moistens and lubricates the mouth and helps to buffer and clean the oral cavity. It also has an antibacterial function and assists in taste and digestion. Human beings have four sets of salivary glands. Parotid glands produce serous saliva, low viscosity, almost watery and account for about $25 \%$ of saliva production in unstimulated state and $70 \%$ in stimulated state [6]. Submandibular glands produce semi-viscous saliva, responsible for $71 \%$ of production in unstimulated state and $25 \%$ when stimulated. The remainder saliva is produced by sublingual glands and minor salivary glands [7].

The medical literature provides consistent data on the use of botulinum toxin in the treatment of sialorrhea, particularly in patients with neurological disorder [8]. However, no study including laryngoscopy to assess the level of saliva aspiration after intraglandular botulinum toxin application was found.

\section{Objective}

To evaluate the reduction of salivation and aspiration after using intraglandular 
botulinum toxin at parotid glands of children with cerebral palsy, through the reduction of the number of bibs reported by the parents and also through the laryngotracheoscopic examination, always carried out by the same researcher.

\section{Method}

This study was approved by the ethics committee of Pequeno Príncipe Hospital under the number: 15293113.5.0000.0097.

The sample size was not as large as we would like, because in our brazilian public health system there is no supply of botulinum toxin for control of sialorrhea. In this case, the author used his own resources for the research or supply of toxin remaining from other specialties throughout the year of research.

The initial sample consisted of 37 patients. However, five of them did not return for the 3-month evaluation and one patient died within this interval.

A prospective cohort study was performed on 31 patients with cerebral palsy treated at the Otolaryngology Department of a tertiary children's hospital in the city of Curitiba.

The patients were aged between 4 and 17 years old. In this study, there were just children with cerebral palsy and sialorrhea. The patient that had received intraglandular botulinum toxin in the past year was excluded from the trial. Furthermore, children with less than 10 kilograms of weight were not included.

The application of intraglandular botulinum toxin type A and laryngotracheoscopy were performed in the operating room under general inhalation anesthesia. Doses of botulinum toxin were calculated based on the weight of the child, with a minimum dose of $10 \mathrm{IU}$ per gland and the maximum dose of $25 \mathrm{IU}$ per gland. The collateral effects, local or systemic, do not manifest if the application does not exceed the recommended value up to $30 \mathrm{U}$ in the parotid and $10 \mathrm{U}$ in the submandibular, when applied [9]. In the study, both brands of botulinum toxin available at the hospital were used-Botox ${ }^{\bullet}$, Dysport $^{\bullet}$, considering the equivalence of drugs. Table 1 shows used doses:

The technique used for toxin application consisted of intraglandular injection by 3 points; the first being $1 \mathrm{~cm}$ anterior to the tragus; the second one, $1 \mathrm{~cm}$ under the start of the third lobe and the third one $1.5 \mathrm{~cm}$ anterior to the tragal notch, approximately in the middle of the other two points. Following illustrative Figure 1.

All patients underwent topical antisepsis with $70 \%$ alcohol, and both the insulin syringe and needle used were sterile and disposable.

Table 1. Doses of botulinum toxin per parotid gland.

\begin{tabular}{cc}
\hline Child's weight in kilograms & UI of borulinum toxin per parotid \\
\hline 10 to 15 & 10 \\
15 to 20 & 15 \\
20 to 25 & 20 \\
Above 25 & 25 \\
\hline
\end{tabular}




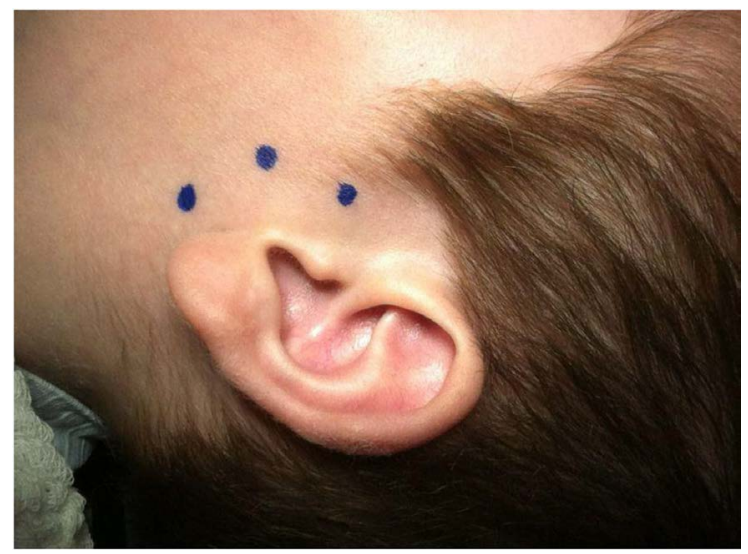

Figure 1. Local application.

Risks inherent to the application are pain and erythema at the injection site, and eventually local hematoma. Infections and abscesses are extremely rare and depend on the antisepsis.

Evaluation of the improvement of sialorrhea observed by the parents was done by quantifying the number of bibs/diapers exchanged per day before and 3 months after the application of intraparotid botulinum toxin.

The laryngotracheoscopic evaluation was always performed by the same physician on the day of the application and 3 months later. The results were defined by the researchers as: Normal Exam, Salivary Stasis, Laryngeal Penetration, Tracheal Aspiration.

The equipment used was the OLYMPUS ENF-P4 nasofibroscope with external diameter of $3.4 \mathrm{~mm}$, coupled to light source. The software used to record the exams was PINNACLE STUDIO.

Data on the number of bibs and laryngotracheoscopic examination were submitted to statistical analysis.

Tests of: Wilcoxon, for analysis of the number of children. Equality between two proportions for exam distribution. Relative frequency distribution for exam evolution.

\section{Results}

The age of 31 children included in research, ranged from 4 to 17 years old, with mean age of 9 years old. 15 were female and 16 were male.

On this study there was an average reduction from 7.35 to 4 bibs after the application of intraparotid botulinum toxin, a statistically significant reduction ( $p$-value $<0.001$ ). As shown in Table 2.

Regarding the laryngotracheoscopic examination, it was observed that there was statistical significance in the distribution of Normal examination, which ranged from 3.2\% to 38.7\% $(p<0.001)$, and in Aspiration distribution, which fell from $38.7 \%$ to $12.9 \%(p<0.02)$, as shown in Table 3 .

The levels of saliva found in the larynx of patients before and after application of botulinum toxin are listed according to Figure 2. 


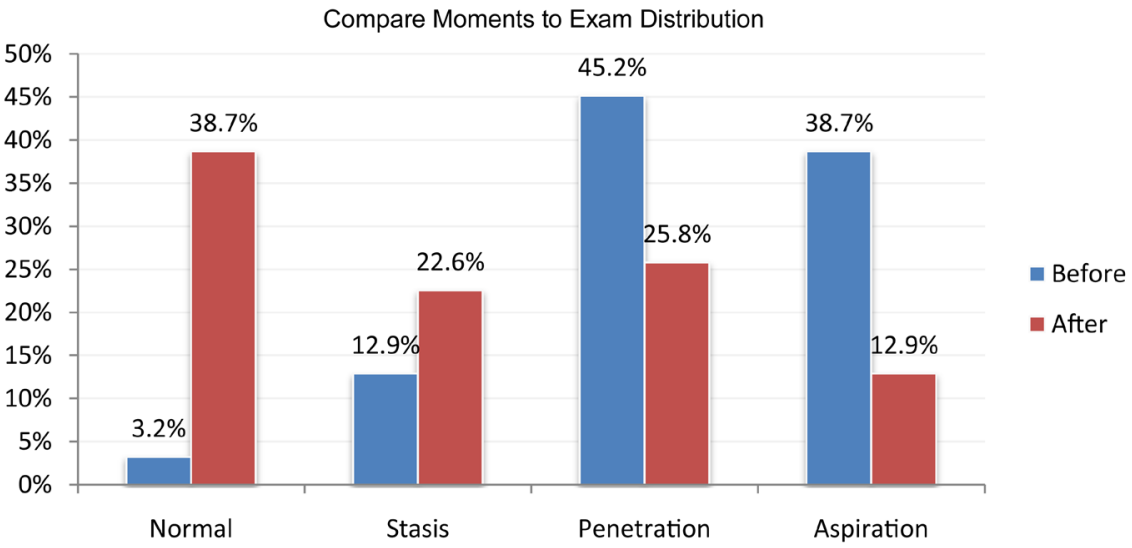

Figure 2. Compare moments to exam distribution.

Table 2. Compare the number of bibs before and three months after the application.

\begin{tabular}{ccc}
\hline Bibs & Before & After \\
\hline Media & 7.35 & 4.00 \\
Median & 5.00 & 3.00 \\
Standard deviation & 5.84 & 3.61 \\
Q1 & 3.50 & 1.50 \\
Q3 & 10.00 & 5.00 \\
N & 31.00 & 31.00 \\
IC & 2.06 & 1.27 \\
$\mathrm{x}$ & & $<0.001$ \\
\hline
\end{tabular}

Table 3. Distribution of the classification for the evolution of the exam.

\begin{tabular}{cccc}
\hline Classification & $\mathrm{N}$ & $\%$ & $P$-value \\
\hline Improvement & 22 & $71.00 \%$ & Ref. \\
Mantained & 7 & $22.60 \%$ & $<0.001$ \\
Worsens & 2 & $6.50 \%$ & $<0.001$
\end{tabular}

This study found that $71.0 \%$ of the subjects improved in some way, being this a statistically significant result in comparison to the others.

Children who had the best results on the laryngotracheoscopic examination were not always the same ones who had the greatest reduction in the number of bibs and vice versa. No child had any collateral effect.

\section{Discussion}

This prospective study happened after the elaboration of an evaluation protocol created by the researchers. The analysis was completed based on the bib exchange data reported by the parents and the results of the laryngotracheoscopy examinations, which were always done by the same examiner. 
Submandibular gland presents some difficulty in being detected only with palpation. Therefore, ultrasound must be performed concomitantly with the application of botulinum toxin in this gland [10]. Most studies do not apply toxin in the submandibular because there is this dependence on the ultrasound.

For this reason and due to the fact that most of the excretion of saliva occurs through the parotids, only the intraparotid injection was used in this study.

Evaluation of sialorrhea through the number of bibs is the easiest way to assess the degree of improvement objectively. Although the amount of saliva to change the bib varies from one caregiver to another, each caregiver has a tendency to change it whenever it reaches a certain amount of saliva. This is the reason why it is a relatively efficient and the most used method by researchers when studying ways to improve sialorrhea [11].

The dynamic study of swallowing by laryngotracheoscopy is less invasive than the deglutogram and can provide data on laryngopharyngeal sensitivity and motricity, as well as being simpler to perform [12].

There are several studies comparing videofluoroscopy with nasofibrolaryngoscopy for the study of swallowing, with agreement that both tests are capable of determining aspiration and its causes with practically the same sensitivity; however, videofluoroscopy evaluates the oral phase well and nasofibrolaryngoscopy evaluates laryngeal and pharyngeal sensitivity [13].

The choice to perform laryngotracheoscopy in this study was because of the facility to do the exam and the fact that there was no control of botulinum toxin application in the literature using this technique.

Through the obtained results it is possible to notice an improvement of $71 \%$ in aspiration levels and a statistically significant reduction on the amount of bibs ( $p$-value $<0.001$ ), suggesting a good application effect of intraglandular toxin, as expected, based on medical literature.

It became very clear through this study that one of the methods of evaluation do not exclude the other one. Since not all patients had objective improvement in the degree of aspiration in laryngotracheoscopy, and improved sialorrhea referred by parents, it is not possible to infer that the sialorrhea improvement will promote an improvement in tracheal aspiration, and vice versa [14], precisely because patients with neurologic disorders have different degrees of deglutition impairment [15]. Three patients had significant salivation on the day of application, but laringotracheoscopy examination three months later was normal with no signs of salivary stasis or aspiration.

Some patients presented an important reduction in the number of bibs, a relief for parents and caregivers, however they remained aspiring on the laryngotracheoscopic exam done after 3 months. For this reason, it is suggested that laryngotracheoscopy should be performed whenever possible in patients undergoing intraglandular botulinum toxin.

Despite the good results obtained in this study and the reviewed articles presented, part of the sample did not respond to the treatment or responded in an unsatisfactory manner. We intend to carry out a new study comparing the ap- 
plication only in the parotid gland in association with submandibular and parotids in order to verify if there are better results.

Our main limitations in this study were the difficulty of returning patients for laryngotracheoscopic control after 3 months of application and the lack of a free supply of botulinum toxin in the public health system for this type of health problem.

\section{Conclusion}

This study showed improvement of sialorrhea with the use of intraparotid botulinum toxin. There was a reduction in the number of bibs in children with cerebral palsy from 7.35 to 4 bibs per day, with $p<0.001$. After 3 months of the application of the toxin, the improvement of the level of saliva in the larynx was $71 \%$, evidenced by laryngotracheoscopy.

\section{References}

[1] Savarese, R., Diamond, M., Elovic, E. and Millis, S. (2004) Intraparotid Injection of Botulinum Toxin A as a Treatment to Control Sialorrhea in Children with Cerebral Palsy. American Journal of Physical Medicine \& Rehabilitation, 83, 304-311. https://doi.org/10.1097/01.PHM.0000104680.28335.B9

[2] Report of the Therapeutics and Technology Assessement Subcommittee, American Academy of Neurology (1990) The Clinical Usefulness of Botulinum Toxin-A in Treating Neurologic Disorders. Neurology, 40, 1332-1336.

[3] Tahmassebi, J. (2007) Prevalence of Drooling in Children with Cerebral Palsy Attending Special Schools. Developmental Medicine \& Child Neurology, 45, 613-617. https://doi.org/10.1111/j.1469-8749.2003.tb00965.x

[4] Reid, S.M., Johnstone, B.R., Westbury, C., et al. (2008) Randomized Trial of Botulinum Toxin Injections into the Salivary Glands to Reduce Drooling in Children with Neurological Disorders. Developmental Medicine \& Child Neurology, 50, 128-132. https://doi.org/10.1111/j.0012-1622.2008.02010.x

[5] Rodwell, K., Edwards, P., Ware, R. and Boyd, R. (2012) Salivary Gland Botulinum Toxin Injections for Drooling in Children with Cerebral Palsy and Neurodevelopmental Disability: A Systematic Review. Developmental Medicine \& Child Neurology, 54, 977-987. https://doi.org/10.1111/j.1469-8749.2012.04370.x

[6] Crysdale, W.S. (2002) The Management of Drooling. In: Bluestone, C.D., Stool, S.E., Alper, C.M., Arjmand, E.M., Casselbrant, M.L., Dohar, J.E. and Yellon, R.F., Eds., Pediatric Otolaryngology, 4th Edition, Saunders, Philadelphia, 1138-1148.

[7] Author (2012) Bioquímica da saliva. seminários UEL. http://www.uel.br/pessoal/buzato/pages/arquivos/seminarios/A1.pdf.pdf

[8] Wilken, B., Aslami, B. and Backes, H. (2008) Successful Treatment of Drooling in Children with Neurological Disorders with Botulinum Toxin A or B. Neuropediatrics, 39, 200-204. https://doi.org/10.1055/s-0028-1112115

[9] Filho, A.F.O., Silva, G.A.M. and Almeida, D.M.X. (2016) Application of Botulinum Toxin to Treat Sialorrhea in Amyotrophic Lateral Sclerosis Patients: A Literature Review. Einstein, 14, 431-434. https://doi.org/10.1590/S1679-45082016RB3594

[10] Alrefai, A., Aburahma, S. and Khader, Y. (2009) Treatment of Sialorrhea in Children with Cerebral Palsy: A Double-Blind Placebo Controlled Trial. Clinical Neurology and Neurosurgery, 111, 79-82. https://doi.org/10.1016/j.clineuro.2008.09.001 
[11] Corso, B.L., Silveira, V.C., Binha, A.M.P. and Chamlitian, T.R. (2011) Abordagem terapêutica na sialorréia em paralisia cerebral: revisão sistemática. Journal of Rehabilitation Medicine, 30, 9-13.

[12] Torres, M.A.F., Aytés, L.B. and Escoda, C.G. (2007) Salivary Gland Application of Botulinum Toxin for the Treatment of Sialorrhea. Medicina Oral Patologia Oral $y$ Cirugia Bucal, 12, 11-17.

[13] Hicks, R., Hartell, M., Nichols, D., Bhattacharjee, A., van Hamont, J. and Skillman, D. (2005) The Medicinal Chemistry of Botulinum, Ricin and Anthrax Toxins. Current Medicinal Chemistry, 12, 667-690. https://doi.org/10.2174/0929867053202223

[14] Vervoorn, K.M. and Vissink, A. (2000) Hypersalivation, Lesions of Oral Mucosa and Generalized Fatigue. Nederlands Tijdschrift Voor Tandheelkunde, 107, 522-524.

[15] Jankovic, J. (2004) Botulinum Toxin in Clinical Practice. Journal of Neurology, Neurosurgery, and Psychiatry, 75, 951-957.

https://doi.org/10.1136/jnnp.2003.034702 